\title{
CHARITÉ
}

UNIVERSITÄTSMEDIZIN BERLIN

\section{Screening for depression and high utilization of health care resources among patients in primary care}

\author{
Anne Berghöfer, Stephanie Roll, Michael Bauer, Stefan N. Willich, \\ Andrea Pfennig
}

\section{Document type \\ Postprint (accepted version)}

This version is available at

https://doi.org/10.17169/refubium-32519

\section{Citation details}

Berghöfer A, Roll S, Bauer M, Willich SN, Pfennig A. Screening for Depression and High Utilization of Health Care Resources Among Patients in Primary Care. [Online] Community Mental Health Journal. Springer Science and Business Media LLC; 2014. p. 753-758.

DOI: 10.1007/s10597-014-9700-4

\section{Terms of use}

All rights reserved. This document is intended solely for personal, non-commercial use.

This version of the article has been accepted for publication, after peer review and is subject to Springer Nature's AM terms of use, but is not the Version of Record and does not reflect post-acceptance improvements, or any corrections. The Version of Record is available on the Springer Nature website: https://www.springernature.com. 
Screening for Depression and High Utilization of Health Care Resources among Patients in Primary Care

Anne Berghöfer, $\mathrm{MD}^{1}$; Stephanie Roll, MSc, $\mathrm{PhD}^{1}$; Michael Bauer, MD, PhD²; Stefan N. Willich, MD, MPH, $\mathrm{MBA}^{1}$; Andrea Pfennig, MD, $\mathrm{MSc}^{2}$

${ }^{1}$ Institute for Social Medicine, Epidemiology and Health Economics, Charité - Universitätsmedizin Berlin, Germany

${ }^{2}$ Department of Psychiatry and Psychotherapy, Carl Gustav Carus University Hospital, Technische Universität Dresden, Germany

Address for correspondence:

Anne Berghöfer, MD

Institute for Social Medicine, Epidemiology and Health Economics

Charité University Medical Center

10098 Berlin

Germany

Tel.: +49 30450529034

Fax: +49 30450529902

anne.berghoefer@charite.de 


\section{Abstract:}

The study aims to evaluate the prevalence of depression and the severity of depressive symptoms among primary care patients, who are high utilizers (HU) of health care resources.

A cross-sectional, two-stage design was applied to screen for depression using the Brief Psychiatric Health Questionnaire and the Diagnostic Expert System for Psychiatric Disorders. A total of 38 primary care physicians accredited to practice in Berlin and Potsdam in Germany participated in the study.

A total of 1,775 patients participated, 507 were identified as high utilizers, $182(36 \%)$ of these were depressed compared to $81(11 \%)$ of the typical utilizers $(\mathrm{p}<0.001)$. The depression score was higher and acute suicidality was more prevalent in high utilizers than in typical utilizers $(\mathrm{p}<0.001)$.

Our results suggest that high utilizers represent a population with a high prevalence of depression in primary care and should be considered for routine depression screening.

Key words: primary care, depression, screening, high utilizer, B-PHQ 


\section{Introduction}

Depression is considered one of the leading causes of disability worldwide (Lopez, Mathers, Ezzati, Jamison, \& Murray, 2006). Various large surveys have detected considerable one-year prevalence figures across countries, ranging from $4 \%$ for any mood disorder (Alonso et al., 2004) to about $6 \%$ for major depression (Bromet et al., 2011).

Most patients with depression first present in a primary care setting (Üstün \& Sartorius, 1996). A large proportion of them, however, remain undiagnosed and untreated due to reasons associated with the illness itself or with structural factors in the health care system. Furthermore, between $45 \%$ and $95 \%$ of depressive patients report only somatic symptoms, depending on the diagnostic setting and their cultural background (Simon, von Korff, Piccinelli, Fullerton, \& Ormel, 1999). Detecting patients with mental health problems in primary care thus remains a considerable challenge.

Various screening tools have been shown to facilitate the detection of mental health problems in primary care. Tools based on a small number of self-reported items have demonstrated acceptable sensitivity (78\% to $93 \%)$ and specificity (62\% to 85\%) for common syndromes such as depression or anxiety (Henkel et al., 2003), and they are straightforward to implement in primary care (Henkel et al., 2004; van Steenbergen-Weijenburg et al., 2010).

Regular screening for depression in primary care, however, has been demonstrated not to be cost-effective, whether conducted on an annual or periodic basis. Indeed, only one-time screening was below the generally accepted limit of \$50,000 per quality-adjusted life year (Valenstein, Vijan, Zeber, Boehm, \& Buttar, 2001). These findings may be due to the poor long-term outcome of depression in general, as well as to the limited effectiveness of treating depression in primary care. The only approaches that have been shown to be effective in treating depression in primary care have been those based on collaborative care or depression treatment algorithms (Neumeyer-Gromen, Lampert, Stark, \& Kallischnigg, 2004; Gilbody, Bower, Fletcher, Richards, \& Sutton, 2006; Adli, Bauer, \& Rush, 2006), but these are still restricted to research and academic settings (Badamgarav et al., 2003). 
It is therefore reasonable to ask whether population-based depression screening should be performed at all in the primary care setting. It might be more effective to focus on patients identified as high utilizers of primary care resources, as measured according to the frequency of physician visits or changes in specialist. Such patients have emerged as having a higher prevalence of depression and anxiety disorders. For a variety of reasons, patients who have mental health problems appear to use health resources at a considerably higher rate than those who do not (Olde Hartman et al., 2008). This may be due to functional impairment, illness-specific behavior, patient interpretations of somatic complaints, or higher levels of stress.

The present study aims to evaluate the prevalence of depression and the severity of depressive symptoms among primary care patients in Germany, who are high utilizers of health care resources.

\section{Methods}

We used a cross-sectional, two-stage design to screen for depression in primary care patients and to assess their utilization of health care resources. All 1,719 primary care physicians accredited to practice in Berlin and the neighboring city of Potsdam in Germany were sent a written invitation to participate in the study, as well as in a subsequent controlled trial. Primary care in Germany is delivered by self-employed physicians who either have no specialization or who specialize in general or internal medicine. They work in solo or small group practices, and provide care to people covered by statutory or private health insurance. A total of 38 primary care physicians in solo practices agreed to participate in this study.

\section{Screening process}

The screening process is shown in Figure 1. Patients who visited a participating primary care physician during 2004 were asked to complete the Brief Patient Health Questionnaire (B-PHQ) while sitting in the waiting room. Completed B-PHQ questionnaires were evaluated by the practice staff with the aid of a scoring template. The physicians and practice staff were trained in the use of the B-PHQ. They had access to a 24/7 telephone hotline staffed by a psychiatric consultant to assist them with any questions. Patients were classified as having major depression if they answered "more than half the days" to at least five of nine depression items, and if at least one of these items involved a core symptom (question 1a "Little interest or pleasure in doing things" or 1b "Feeling down, depressed, or hopeless"). Patients were classified as having "other depression" if they answered "more 
than half the days" to between two and four of the items, and if at least one of the these items involved a core symptom (Coding Algorithm according to Spitzer) (Spitzer, Kroenke, \& Williams, 1999).

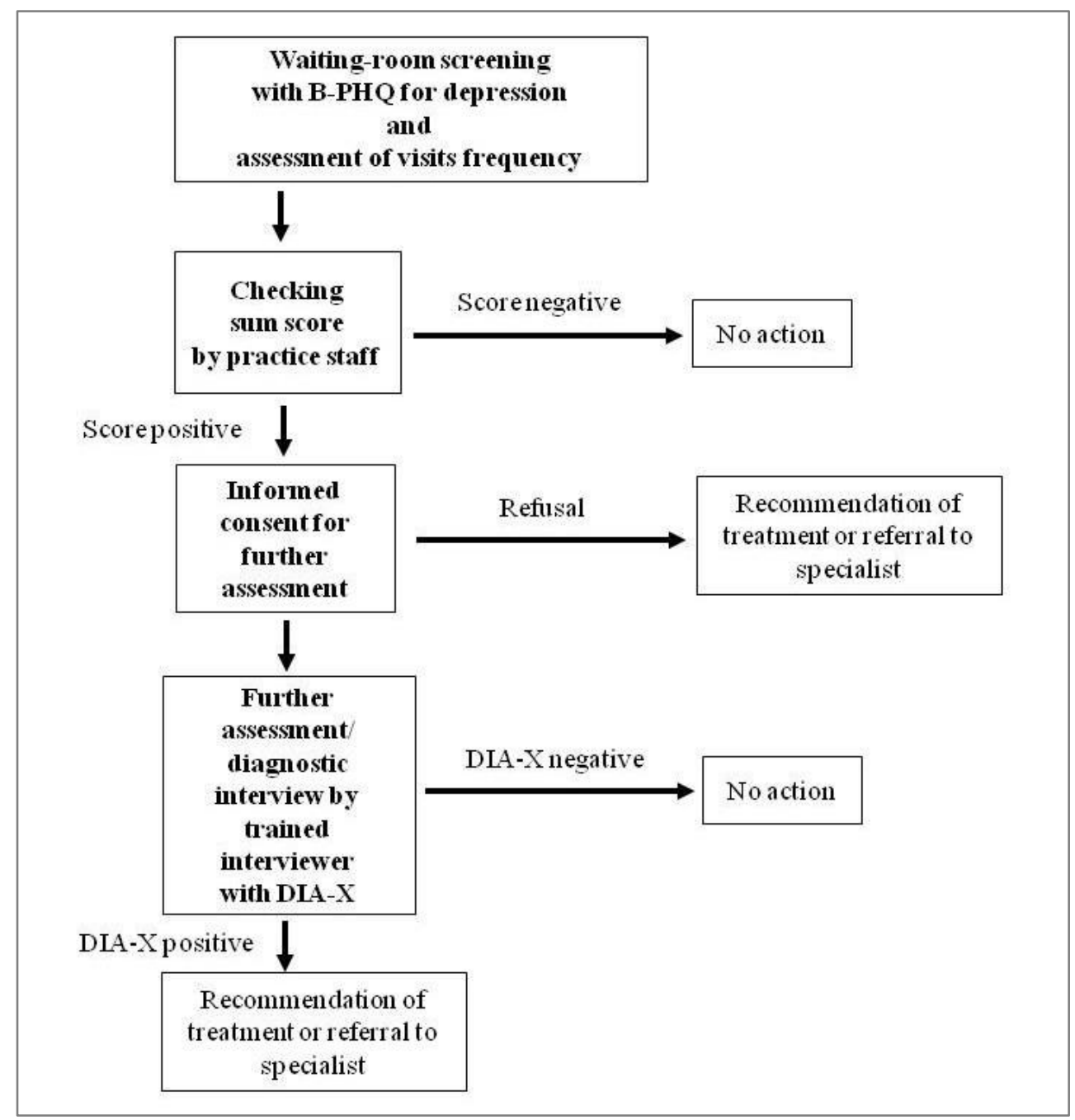

Figure 1: Screening process for depression in primary care among high utilizers of health care resources

In order to identify high utilization of health care resources, practice staff used either their standard computerized patient documentation system, if available, or an additional question added to the B-PHQ asking the patient about the frequency of physician visits. A patient was defined as being a high utilizer if he or she had visited the primary care physician or a specialist at least 5 times during the most recent, completed calendar quarter. Like primary care physicians, most specialists in Germany work on a self-employed basis in solo or group practices.

Patients who screened positive for depression in the B-PHQ and were identified as high utilizers were given details about participating in further diagnostic assessment. In cases where patients subsequently provided written, informed consent, their contact details were sent to the study coordinating center by fax. Diagnoses were 
validated at the coordinating center by trained, supervised medical student interviewers using the Diagnostic Expert System for Psychiatric Disorders (DIA-X). Finally, the coordinating center staff informed the participating primary care physicians by fax about the findings of the diagnostic instrument and provided recommendations for treatment or assisted with referral to specialists. Patients were eligible for inclusion in a subsequent randomized controlled trial of a standardized intervention plan, the results of which have been reported elsewhere (Berghöfer et al., 2012).

\section{Diagnostic instruments}

The Brief Patient Health Questionnaire (B-PHQ) is a short self-report instrument extracted from the PRIME-MD Patient Health Questionnaire (Spitzer et al., 1999; Kroenke, Spitzer, \& Williams, 2001). The B-PHQ is the standard tool for routine diagnostic assessment within the German health care system and therefore does not require informed consent. It has been validated, showing a sensitivity of $79 \%$ and a specificity of $86 \%$ (Henkel et al., 2003). Sum scores equal to or great than 5, 10, 15, or 20 in the 9-item version represent mild, moderate, moderately severe, or severe depression, respectively (Kroenke et al., 2001). The Diagnostic Expert System for Psychiatric Disorders (DIA-X) is a standardized, computer-based diagnostic telephone interview (World Health Organisation, 1990; Wittchen \& Semler, 1991; Wittchen \& Pfister, 1997) and was conducted by trained, supervised medical student interviewers.

\section{Statistical analysis}

Statistical analysis was performed with SPSS Version 19 (Brosius, 2011). Major and minor depression were diagnosed according to the coding algorithm described above and proposed by Spitzer et al. (Spitzer et al., 1999). All data were tested for normal distribution. As the data did not show normality, comparisons were performed using non-parametric tests. Differences in the distributions of both groups were analyzed using the Mann-Whitney U test, whereas differences in binary variables were analyzed using the chi-square test.

The study protocol was reviewed and approved by the local University Ethics Board (Charité Universitätsmedizin Berlin, Germany). It was determined that the screening phase did not require informed consent, as a routine diagnostic instrument was used. All patients gave written, informed consent before undergoing further assessment to confirm their diagnosis. The study adhered to the Declaration of Helsinki. 


\section{Competing Interests}

The study was supported by Pfizer GmbH, Karlsruhe, by a limited grant. The authors have no financial or nonfinancial competing interests.

\section{Authors' Contributions}

$\mathrm{AB}$ and AP made substantial contributions to the study conception and design, acquisition of data, analysis and interpretation of data, and drafting of the manuscript. MB, SR and SW were involved in study conception and in drafting the manuscript. All authors have read and approved the final manuscript and certify responsibility.

\section{Results}

Approximately 19,000 patients visited the 38 participating practices in 2004 . All patients were invited to take part in the study, and 1,775 chose to participate (figure 2). The utilization of health care resources could be determined in 1,260 (71\%) patients. Of these patients, $507(40 \%)$ were high utilizers and $753(60 \%)$ were typical utilizers. For 515 patients (29\%), the frequency of visits could not be determined, because neither the patient nor the physician was able to provide this information (see figure 2). A total of 263 of the 1,260 patients (21\%) screened as having major depression. Altogether $182(36 \%)$ of the high utilizers were depressed compared to 81 $(11 \%)$ of the typical utilizers $(\mathrm{p}<0.001)$.

High utilizers had a significantly higher number of physician visits during the most recent completed calendar quarter compared to typical utilizers (median (range) 7 (5 - 36) vs. $2(1-4), \mathrm{p}<0.001)$. The median B-PHQ depression module summary score was significantly higher in high utilizers than in typical utilizers (median (range) $8(0-26)$ vs. $4(0-26), \mathrm{p}<0.001)$. Moreover, high utilizers were significantly more likely than typical utilizers to have screened positive for minor or major depression $(\mathrm{p}<0.001)$. High utilizers were also significantly more likely than typical utilizers to have reported low or severe suicidality $(\mathrm{p}<0.001)$ (table 1$)$. 


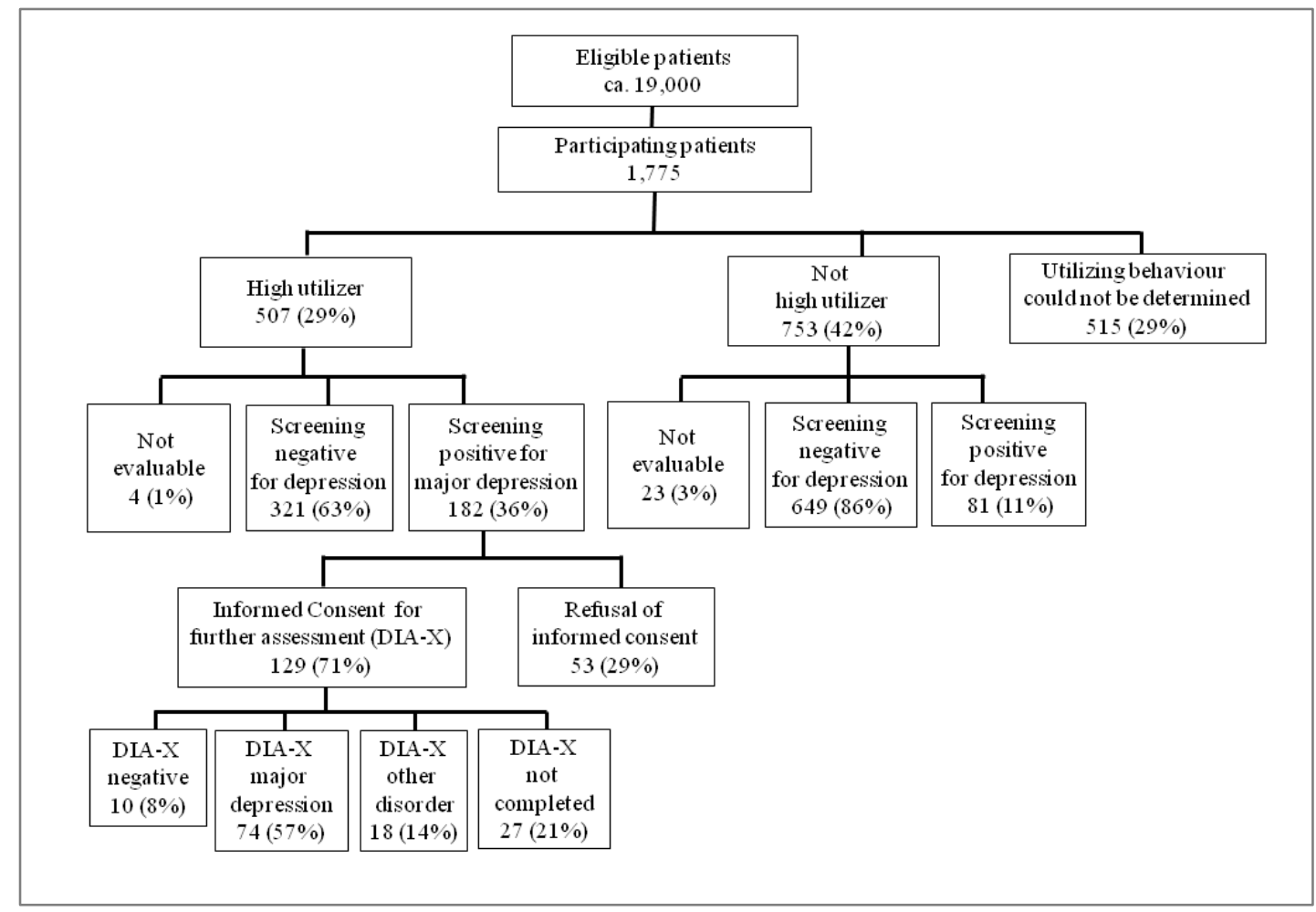

Figure 2: Patient flow during recruitment and screening process (DIA-X = Diagnostic Expert System for Psychiatric Disorders)

Table 1: Depression prevalence and characteristics of high utilizers and typical utilizers in primary care (B$P H Q=$ Brief Psychiatric Health Questionnaire). Higher B-PHQ depression scores indicate more severe depressive symptoms.

\begin{tabular}{|c|c|c|c|}
\hline & $\begin{array}{l}\text { High utilizers } \\
\mathrm{n}=507\end{array}$ & $\begin{array}{l}\text { Typical utilizers } \\
\mathrm{n}=753\end{array}$ & p value \\
\hline & median (range) & median (range) & \\
\hline $\begin{array}{l}\text { Number of visits during most } \\
\text { recent, completed calendar } \\
\text { quarter }\end{array}$ & $7(5-36)$ & $2(1-4)$ & $<0.001 *$ \\
\hline $\begin{array}{l}\text { Depression score on } \\
\text { B-PHQ questionnaire }\end{array}$ & $8(0-26)$ & $4(0-26)$ & $<0.001^{*}$ \\
\hline & $\mathrm{n}(\%)$ & $\mathrm{n}(\%)$ & \multirow{4}{*}{$<0.001^{\#}$} \\
\hline Major depression & $182(36.3)$ & $81(11.1)$ & \\
\hline Minor depression & $21(4.2)$ & $15(2.1)$ & \\
\hline No depression & $298(59.5)$ & $631(86.8)$ & \\
\hline Severe suicidality & $43(8.5)$ & $15(2.0)$ & \multirow{3}{*}{$<0.001^{\#}$} \\
\hline Low suicidality & $108(21.3)$ & $69(9.2)$ & \\
\hline No suicidality & $356(70.2)$ & $669(88.8)$ & \\
\hline
\end{tabular}

\footnotetext{
* Mann-Whitney U test ${ }^{\#}$ chi-square test
} 
In total, $129(25 \%)$ of the high utilizers gave informed consent to further diagnostic assessment. Of these patients, $10(8 \%)$ were evaluated as not being depressive according to the DIA-X and $18(14 \%)$ as having other psychiatric diagnoses (4 bipolar disorder, 3 dysthymia, 11 anxiety disorder or somatization disorder). Altogether $27(21 \%)$ patients did not complete the diagnostic interview due to language or communication difficulties, or were immediately referred to specialized psychiatric treatment because of acute suicidal thoughts. A subgroup of 63 high utilizers with major depression participated in a subsequent randomized treatment trial. The sociodemographic and clinical characteristics of this subgroup are given in table 2 . In this group, $44 \%$ had a low household income and $22 \%$ were unemployed.

Table 2: Sociodemographic and clinical characteristics of 63 high utilizers with moderate or severe major depression (B-PHQ = Brief Psychiatric Health Questionnaire).

\begin{tabular}{|l|l|l|}
\hline & $\mathrm{N}$ & $\%$ \\
\hline Men & 17 & 27.0 \\
\hline Living alone, separated, or divorced & 26 & 41.3 \\
\hline Net household income < 1,000 euros & 22 & 43.9 \\
\hline Elementary school or no graduation & 20 & 31.7 \\
\hline Unemployed & 14 & 22.2 \\
\hline Retired & 11 & 17.5 \\
\hline On sick leave (of 38 working-age patients) & 33 & 86.8 \\
\hline Somatic illness & 53 & 84.1 \\
- cardiovascular disease & 22 & 41.5 \\
- diabetes & 6 & 11.3 \\
\hline - chronic pain syndrome & 34 & 64.2 \\
\hline & Median & Range \\
\hline Age & 51 & $22-93$ \\
\hline B-PHQ depression summary score in screening & 14 & $5-23$ \\
\hline
\end{tabular}

\section{Discussion}

Among 1,775 patients screened for depression in the primary care setting in Germany, about one third were identified as being high utilizers of health care resources, including primary care and specialist services. Of these high utilizers, one third screened positive for major or minor depression. These patients had a significantly higher B-PHQ depression score and were significantly more likely to have had suicidal symptoms compared to 
typical utilizers. These results are in line with other reports on depression in high utilizers (Katon et al., 1990; Press, Tandeter, Romem, Hazzan, \& Farkash, 2012).

A subgroup of depressed high utilizers who gave informed consent to undergo detailed psychiatric assessment could be characterized as disadvantaged in terms of social relations, education, and income. These patients also exhibited above-average somatic comorbidity.

The average prevalence of major depression in the group with known utilization was $21 \%$ (263 out of 1260), which is higher than has been reported in other studies of depression screening in primary care (Klinkman, Coyne, Gallo, \& Schwenk, 1997; King et al., 2008; Katon, 1987).

This study has several important limitations. First, the response rate among physicians invited to participate was very low, potentially leading to a disproportionate number of physicians in the sample with a special interest in the detection or treatment of depression. Care must therefore be taken when generalizing the results to the broader physician population.

Second, the overall willingness of patients to participate in screening was relatively low. Less than $10 \%$ of those who presented to the participating primary care physicians completed the short questionnaire. Those who participated may have been more willing to complete the form because they had mental complaints or disorders, whereas those who felt well may have tended to decline participation. The results of the screening may therefore overestimate the prevalence of depressive symptoms in primary care.

Third, the screening did not determine confounding variables such as severity of somatic illness or sociodemographic variables. As the B-PHQ is considered a routine instrument in primary care, we did not need informed consent from the patients as long as no additional personal information was collected. Informed consent was required only for the second stage of screening, which used the DIA-X and involved collecting additional sociodemographic information. As a result, the prevalence of depression observed in high utilizers and typical utilizers could not be adjusted for possible sociodemographic differences between patients. Potential confounding of this nature, however, is not relevant to the primary aim of the study, which was to identify depressed patients and facilitate antidepressant treatment. Even if the high utilization observed in this study was due mainly to old age and somatic morbidity, any undetected depression should ideally be diagnosed and treated. 
Fourth, the number of physician visits could not be determined in almost one third of the participating patients. In these cases, physicians did not have the necessary information because the patients were attending the practice for the first time or could not remember the information themselves. It is conceivable that these patients were younger, had fewer physician visits, and had a lower risk of depression. This would also lead to an overestimation of depression prevalence in the screened sample.

Fifth, among the 129 high utilizers who gave informed consent for further assessment to confirm their diagnosis, 10 were diagnosed as not being depressive according to the DIA-X. Due to a delay of up to 3 weeks between the screening visit in the primary care practice and the DIA-X appointment, these patients may have already remitted. The results may therefore simply reflect regression to the mean. Another 18 patients were diagnosed with psychiatric disorders other than major depression and referred to secondary care. Short screening instruments like the B-PHQ in primary care are not specific for major depressive disorder, but rather for depressive symptoms that might also appear with other psychiatric diagnoses. This is not necessarily a disadvantage of this instrument, as detecting any mental disorder in primary care can be advantageous by facilitating further specialized diagnostics and care.

Finally, due to the cross-sectional design of the study, it is impossible to establish whether depression is a risk for the high utilization of health care resources or rather a consequence of chronic somatic illness. This is not relevant, however, to the primary aim of the study, which, as noted above, was to evaluate a simple method for identifying depressed patients to facilitate appropriate treatment.

\section{Conclusions}

Screening for major depression in primary care detected a higher prevalence in patients who were high utilizers of health care resources, including primary care and specialist services. Programs that integrate systematic screening and treatment algorithms may facilitate adequate diagnosis and treatment of major depression in the primary care setting. The results of this study suggest that high utilizers represent a population with a high prevalence of depression in primary care and should therefore be considered for routine depression screening. 
Adli, M., Bauer, M., \& Rush, A. J. (2006). Algorithms and collaborative-care systems for depression: are they effective and why? A systematic review. Biol.Psychiatry., 59, 1029-1038.

Alonso, J., Angermeyer, M. C., Bernert, S., Bruffaerts, R., Brugha, T. S., Bryson, H. et al. (2004). Prevalence of mental disorders in Europe: results from the European Study of the Epidemiology of Mental Disorders (ESEMeD) project. Acta Psychiatr.Scand.Suppl, 21-27.

Badamgarav, E., Weingarten, S. R., Henning, J. M., Knight, K., Hasselblad, V., Gano, A., Jr. et al. (2003). Effectiveness of disease management programs in depression: a systematic review. Am.J.Psychiatry., 160, 2080-2090.

Berghöfer, A., Hartwich, A., Bauer, M., Unützer, J., Willich, S. N., \& Pfennig, A. (2012). Efficacy of a systematic depression management program in high utilizers of primary care: a randomized trial. BMC.Health Serv.Res., 12, 298.

Bromet, E., Andrade, L. H., Hwang, I., Sampson, N. A., Alonso, J., de, G. G. et al. (2011). Cross-national epidemiology of DSM-IV major depressive episode. BMC.Med., 9, 90.

Brosius, F. (2011). SPSS 19. (1. Auflage ed.) Verlagsgruppe Hüthig-Jehle-Rehm.

Gilbody, S., Bower, P., Fletcher, J., Richards, D., \& Sutton, A. J. (2006). Collaborative care for depression: a cumulative meta-analysis and review of longer-term outcomes. Arch.Intern.Med., 166, 2314-2321.

Henkel, V., Mergl, R., Coyne, J. C., Kohnen, R., Moller, H. J., \& Hegerl, U. (2004). Screening for depression in primary care: will one or two items suffice? Eur.Arch.Psychiatry Clin.Neurosci., 254, 215-223.

Henkel, V., Mergl, R., Kohnen, R., Maier, W., Moller, H. J., \& Hegerl, U. (2003). Identifying depression in primary care: a comparison of different methods in a prospective cohort study. BMJ., 326, 200-201.

Katon, W. (1987). The epidemiology of depression in medical care. Int.J.Psychiatry Med., 17, 93-112.

Katon, W., Von, K. M., Lin, E., Lipscomb, P., Russo, J., Wagner, E. et al. (1990). Distressed high utilizers of medical care. DSM-III-R diagnoses and treatment needs. Gen.Hosp.Psychiatry., 12, 355-362.

King, M., Nazareth, I., Levy, G., Walker, C., Morris, R., Weich, S. et al. (2008). Prevalence of common mental disorders in general practice attendees across Europe. Br.J Psychiatry, 192, 362-367.

Klinkman, M. S., Coyne, J. C., Gallo, S., \& Schwenk, T. L. (1997). Can case-finding instruments be used to improve physician detection of depression in primary care? Arch.Fam.Med., 6, 567-573.

Kroenke, K., Spitzer, R. L., \& Williams, J. B. (2001). The PHQ-9: validity of a brief depression severity measure. J.Gen.Intern.Med., 16, 606-613.

Lopez, A. D., Mathers, C. D., Ezzati, M., Jamison, D. T., \& Murray, C. J. (2006). Global and regional burden of disease and risk factors, 2001: systematic analysis of population health data. Lancet, 367, 1747-1757.

Neumeyer-Gromen, A., Lampert, T., Stark, K., \& Kallischnigg, G. (2004). Disease management programs for depression: a systematic review and meta-analysis of randomized controlled trials. Med.Care, 42, 1211-1221.

Olde Hartman, T., van, R. E., van, R. H., Hassink-Franke, L., Bor, H., van Weel-Baumgarten, E. et al. (2008). Mental health problems and the presentation of minor illnesses: data from a 30-year follow-up in general practice. Eur.J.Gen.Pract., 14 Suppl 1, 38-43.

Press, Y., Tandeter, H., Romem, P., Hazzan, R., \& Farkash, M. (2012). Depressive symptomatology as a risk factor for increased health service utilization among elderly patients in primary care. Arch.Gerontol.Geriatr., $54,127-130$.

Simon, G. E., von Korff, M., Piccinelli, M., Fullerton, C., \& Ormel, J. (1999). An international study of the relation between somatic symptoms and depression. N.Engl.J.Med., 341, 1329-1335.

Spitzer, R. L., Kroenke, K., \& Williams, J. B. (1999). Validation and utility of a self-report version of PRIMEMD: the PHQ primary care study. Primary Care Evaluation of Mental Disorders. Patient Health Questionnaire. JAMA, 282, 1737-1744.

Üstün, T. B. \& Sartorius, N. (1996). Mental Illness in General Health Care. An Intewrnational Study. Chichester: Wiley.

Valenstein, M., Vijan, S., Zeber, J. E., Boehm, K., \& Buttar, A. (2001). The cost-utility of screening for depression in primary care. Ann.Intern.Med., 134, 345-360.

van Steenbergen-Weijenburg, K. M., de Vroege, L., Ploeger, R. R., Brals, J. W., Vloedbeld, M. G., Veneman, T. F. et al. (2010). Validation of the PHQ-9 as a screening instrument for depression in diabetes patients in specialized outpatient clinics. BMC.Health Serv.Res., 10, 235.

Wittchen, H. U. \& Pfister, H. (1997). Diagnostisches Expertensystem für Psychische Störungen. DIA-X Instruktionsmanual bzw. Interview. Frankfurt: Swets \& Zeitlinger.

Wittchen, H. U. \& Semler, G. (1991). Composite International Diagnostic Interview Schedule (CIDI). Weinheim: Beltz Test Verlag.

World Health Organisation (1990). ICD-10, Chapter V. Mental and behavioural disorders (including disorder of psychopathological development): a) Diagnostic guidelines, b) Diagnostic criteria for research. Geneva: World Health Organisation. 